\title{
Laicos e Iglesia
}

\section{1.- La palabra "laico".}

En principio, "laico" parece ser un término ambiguo. Sin embargo, no lo es tanto. Proviene del vocablo griego laós, "pueblo", visto generalmente desde el aspecto concreto de "masa", multitud, gente sin más, calificación que le distingue bien de sus líderes, la aristocracia dirigente, educada o rica1. Laós no tendría el sentido de pueblo considerado desde su unidad, "nación", basado en lazos históricos, lingüísticos o culturales, sino considerado desde su multiplicidad e indefinición. Nuestro uso de la palabra pueblo aclara esto perfectamente. El primer sentido que le damos en castellano es el de, según decimos, "pueblo llano", gente no especialmente distinguida (significa también "población rural"). Sólo en el lenguaje solemne, político o religioso, se emplea en el sentido de nación, comunidad de personas unidas entre sí por algún lazo, abarcando el conjunto (en este caso muchas veces necesita ser adjetivado, "pueblo español", "pueblo de Dios"). El adjetivo laikós significará, según esto, "plebeyo", perteneciente al pueblo simple, quien no destaca particularmente y se pierde en la masa social.

Trasladado a un contexto religioso mantiene el mismo significado. Laós se refiere al pueblo sin especificaciones, a la gente que asiste al culto, contrapuesta a quienes lo dirigen, los sacerdotes. Como el sacerdote es el hombre sagrado (hierós, sagrado; hiereús, sacerdote) laikós indicará la persona "no

1. H. StRathmanN, Laós, en Theologisches Wörterbuch zum Neuen Testament IV, 2957; W. Grundmann, Démos, ibid II, 62-64; G. Bertram - K.L. Schmidt, Éthnos, ibid II, 362-370; I. De LA POTTERIE, L'origine et le sens primitive du mot "laïc", en I. DE LA POTTERIE - S. LYONNET, La vie selon l'esprit, París 1965, 13-29. 
consagrada" y, en este sentido, "profana"2. Laós y laikós, de todos modos, se mantienen en la esfera de la acepción de pueblo bajo, sencillo, de a pie 3 .

La traducción griega del Antiguo Testamento de los LXX realizó una pequeña revolución semántica con la palabra laós. La reservó para designar la peculiaridad de Israel entre todos los pueblos, ser el pueblo elegido de Dios. Como ésta era una palabra antigua, no muy utilizada en su época, sino más bien con una aureola poética y de lenguaje elevado, pareció la más adecuada para expresar esto 4 . En los LXX laós significa masivamente "pueblo de Dios", diferenciado del resto de los pueblos, éthne. La conciencia de superioridad respecto de los demás pueblos, algo por lo demás común a otras civilizaciones -griegos y romanos conocían a las gentes extranjeras como "bárbaros"-, que Israel fundamentó en el plano religioso, encontró su reflejo lingüístico en griego exclusivizándose la palabra laós.

De este modo laós pasó a significar en la Escritura pueblo en cuanto unidad, nación, revesando el significado anterior. Sin embargo, no perdió su antigua acepción de gente o multitud. Por un lado, laós también se aplica a la masa del pueblo israelita, distinguida de sus cabezas, como sacerdotes, profetas (por ejemplo Ex 19,24; Jer 26,7; Os 4,9). Y por otro, el adjetivo laikós, que en la teología veterotestamentaria de la elección parecería llevar a designar "israelita", perteneciente al laós, no existe en los LXX. Tal vez porque esta palabra conservaba el sentido de "no consagrado", profano, dado el contexto religioso del Antiguo Testamento, lo que chocaba con la teología del pueblo elegido, "reino de sacerdotes, nación santa" (Ex 19,6). Laós, por tanto, sólo habría servido para solucionar terminológicamente la conciencia israelita de ser predilección divina frente al resto de naciones. Pero no ha perdido su significado básico de pueblo simple. Esto se confirma en otras versiones griegas del Antiguo Testamento y en el Nuevo Testamento.

En las traducciones griegas del Antiguo Testamento del s. II, manteniendo el significado de laós creado en los LXX, sí aparece el adjetivo laikós, siempre con el sentido de "no consagrado" y siempre aplicado a cosas, no a personas 5 . En el Nuevo Testamento, al contrario que en los LXX, el significado predominante de laós no es el de comunidad nacional, sino el de gente, multitud. Naturalmente que sigue la estela del Antiguo Testamento y cuando se habla de laós se piensa en el pueblo elegido, pero insistiendo en la con-

2. De aquí ha derivado, por extensión, el actual significado de laico como "arreligioso".

3. Hay que decir que estos términos resaltan el aspecto de "anonimato" de los así designados, y no conllevan necesariamente, aunque sí frecuentemente, un matiz peyorativo.

4. H. STRATHMANN, o.c., 35.

5. Cf. I. DE LA PotTERIE, o.c., 19, que analiza estos pasajes -1Sam 21,5-6; Ez 22,26; 48,15- en las traducciones de Aquila, Símmaco y Teodoción. 
notación popular, la muchedumbre israelita, diferenciada de sus líderes (Mt 26,5; Mc 11,32; Lc 1,21; Hch 13,15, etc). El adjetivo laikós, por su parte, no aparece en el Nuevo Testamento.

De todo esto se puede concluir que las palabras laós y laikós son bastante unívocas. Dentro de las normales fluctuaciones aceptivas de toda palabra, laós se ha originado y mantenido con cierta continuidad como expresión del pueblo sencillo, de las capas anónimas sociales, en sentido cultural, religioso o político, niveles que suelen ser fácilmente intercambiables. Derivando de esta palabra, laikós se referirá al súbdito, inculto, no sacerdote (profano, no consagrado). La Iglesia cristiana, utilizando a lo largo de su historia la palabra laico, ha conservado de modo más o menos uniforme esta misma significación.

\section{2.- Evolución de "laico" en la Iglesia.}

Cuando la Iglesia introdujo la palabra láico en su seno sobreentendió su sentido religioso, quien no es sacerdote, y también la connotación de ausencia de poder que le es original, por tanto, quien no gobierna la comunidad. Esto se percibe claramente en el primer texto cristiano que aporta la palabra laico a la estructura eclesial, la llamada Primera Carta de Clemente a los Corintios.

\section{a) Una carta de Roma.}

No parece casual que la carta de "la iglesia de Dios que habita como forastera en Roma a la iglesia que habita como forastera en Corinto" (1Clem, Introducción $)^{6}$, sea el primer documento cristiano que lleve la palabra laico. El escrito, fechado entre el primer y segundo siglo de nuestra era, está dominado por la relación obediencia-autoridad en la iglesia. Repite constantemente las palabras orden, humildad, obediencia. Le parece el único modo de resolver y evitar enfrentamientos en el interior de la comunidad.

Detonante de la carta fue una áspera división entre los corintios. $\mathrm{O}$ mejor, una sublevación de la comunidad corintia contra sus dirigentes, que la llevó a deponerlos. Los corintios, que en otro tiempo caminaban sometidos a sus dirigentes (1Clem 1,3), que era más amigos "de obedecer que de mandar" $(2,1)$, han cometido una "sedición extraña y ajena a los elegidos de Dios, abominable y sacrílega" $(1,1)$, destituir a sus presbíteros-epíscopos

6. Carta primera de san Clemente a los Corintios, en D. Ruiz BuEno, Padres Apostólicos, Màdrid 1950, 177-238; ClÉMENT DE ROME, Épitre aux Corinthiens (Sources Chretiennes 167, ed. A. JAUBERT), París 1971. 
(estos ministerios todavía no se diferencian entre sí). "Vemos que vosotros habéis removido de su ministerio a algunos que lo honraron con conducta santa e irreprochable" $(44,6)$, lamenta la carta. Este es el conflicto existente en la iglesia corintia, que causó una escisión en la comunidad a la que no se encontraba salida, y que motivó la intervención de la iglesia romana.

La solución que da la carta es reintegrar en sus funciones a los ministros derrocados. No se consideran las razones de la sublevación. En realidad no parecen importar. Sencillamente es vergonzoso que una comunidad cristiana, y más "la firmísima y antigua iglesia de los corintios" $(47,6)$, se rebele contra sus presbíteros. El problema, y la solución, es encuadrado desde la relación que debe existir con la autoridad. A ésta se debe sumisión y basta. Por ello se ensalzan constantemente la humildad y la obediencia, como si fueran las mejores virtudes comunitarias, y se cita abundantemente a personajes del Antiguo Testamento y a Cristo como modelos de ellas (10,1-3.7; $16,1-3.17 ; 17-18)$. El orden es otra obsesión de la carta de Clemente. La premisa mayor es que no se debe trastocar el orden establecido, querido por Dios, cada uno debe mantenerse en el lugar que ocupa $(21,5 ; 38,1 ; 41,1)$. Como ejemplos de orden, y por tanto a imitar por la iglesia, se proponen el ejército (37,2-4), donde escalonadamente unos mandan y otros obedecen, el cuerpo humano (37,5), como ya hiciera Pablo a la misma comunidad (1Cor 12,12-30), aunque en distintas circunstancias ${ }^{7}$, y la jerarquía religiosa paleotestamentaria (40-41), donde aparece el vocablo laico.

En este último contexto de elogio del orden jerárquico y cúltico del Antiguo Testamento -que fija los tiempos, los lugares, las personas, el modo, en la alabanza divina-, se dice que "al sumo sacerdote de la antigua Ley le estaban encomendados sus propias funciones; su propio lugar tenían señalados los sacerdotes ordinarios, y sus propios ministerios incumbían a los levitas; el hombre laico (laikós ánthropos), en fin, por preceptos laicos (laikoís prostágmasin) está ligado" (40,5).

Si todavía no existe en la Iglesia una distinción estructural entre ministros ordenados y laicos se está ya muy cerca de ello ${ }^{8}$. Naturalmente que se

7. En Pablo se debió al desorden y rivalidad provocados por la efervescencia carismática de los corintios, que buscaban poseer los "mejores" carismas, y así habló del cuerpo como ejemplo de armonía y complementariedad en la diversidad. En 1Clem se debe a una especie de motín contra los presbíteros, y se insiste en la necesaria unidad y correspondencia entre la cabeza y los pies.

8. A. Faivre (Les laïcs aux origines de l'Église, París 1984, 36s) insiste en que no se da el laicado como estructura eclesial hasta el siglo III. Las palabras de 1Clem son sólo una inadecuada comparación. Por el contrario, para A. Jaubert, en su introducción a la Carta de Cle- 
está hablando del Antiguo Testamento, pero su organización cúltica se propone a la Iglesia. No hay que olvidar que los cristianos consideraban la historia de Israel como prefiguración de la propia (1Cor 10,6.11; 1Pe 3,20s), y la Carta de Clemente abunda en este sentido. Por otra parte, la distinción clerolaicado aparece un siglo más tarde en los escritos cristianos de modo tan frecuente y natural que hay que pensar que existía desde tiempo atrás, aunque no tengamos testimonios de ello.

El buen orden religioso y comunitario de la Antigua Alianza es ofrecido como paradigma a imitar, particularmente adecuado para la iglesia de Corinto en la difícil situación que atraviesa. Es el espejo en el que debe mirarse. Pues bien, como en el Antiguo Testamento, el "hombre laico", quien no es sacerdote ni levita $-\mathrm{y}$ en nuestro caso, diría $1 \mathrm{Clem}$, quien no pertenece al episcopado-presbiterado ni al diaconado-, debe someterse a sus jefes. No puede usurpar su puesto, debe contentarse con los "preceptos laicos". Sólo así puede haber orden y armonía en la comunidad.

"Laico" para 1 Clem es quien no tiene una función dirigente u organizativa, quien debe acatar el mando de quienes la tienen. Por eso la revuelta corintia está fuera de lugar en la Iglesia, es "extraña y ajena a los elegidos de Dios", denota arrogancia, soberbia, envidia, para decirlo con sus palabras. Han cometido un "pecado nada pequeño" $(44,4 ; 59,1)$ y deberán pedir perdón, "someter su cuello, y ocupando el lugar de la obediencia, rendirse a los que son guías de nuestras almas" $(51 ; 63,1)$. Laico, pues, sigue significando lo mismo: quien obedece. Dado el contexto religioso, laico es también el profano, no consagrado, no sacerdote. Por eso la sedición es calificada de "abominable y sacrílega". Comprobamos de nuevo que la asimilación entre líderes cristianos y sacerdotes, de un lado, y simples cristianos y laicos, de otro, está prácticamente cerrada. Al laico no atañen las cuestiones sagradas, que corresponden a los sacerdotes, sino las cosas profanas, los preceptos laicos ${ }^{9}$. Las negativas consecuencias que derivan de esta concepción prenderán fuertemente en la iglesia.

mente (Sources Chretiennes 167, 81-83), se insinúa ya una correspondencia entre la jerarquía del Antiguo Testamento y el orden eclesial, sacerdotes-levitas-laicos y epíscopos-diáconosfieles.

9. La más antigua versión latina de 1 Clem tradujo de distinto modo laikós según se refiriera a una persona o a una cosa: Plebeius homo laicis praeceptis datus est (Cf. D. RuIZ Bueno, o.c., 255). No aplica la palabra laico a las personas sino sólo a las cosas. Le pareció demasiado negativa (A. FAIVRE, o.c., 35), seguramente por su connotación de "profano". Prefiere plebeius, quien pertenece al pueblo anónimo y dirigido. 
b) Clero y laicado.

Tras la Carta de Clemente no volvemos a encontrar la palabra laico en los escritos cristianos hasta un siglo después. Los autores del siglo II, como Justino e Ireneo, la ignoran completamente. Pero a principios del siglo III se ha generalizado tanto que ya es un término común. Designa una estructura bien delimitada dentro de la Iglesia, que la diferencia de otra, el clero. Son palabras que han nacido y crecido juntas en la Iglesia para nombrar dos estamentos distintos, hijos gemelos cada vez más enfrentados. Al mismo tiempo parte del clero se asimila al sacerdocio, término que hasta entonces los cristianos habían rehuido en cuanto institución especial. Lo que en la Carta de Clemente estaba apuntado observamos ya plenamente crecido. Laicos son la plebs, distinguidos de sus cabezas y pastores, el ordo sacerdotal o clero, esto es, obispos, presbíteros y diáconos. Testimonio de ello son los escritos de Tertuliano, Clemente de Alejandría y Orígenes ${ }^{10}$.

La palabra griega kléros significa literalmente "sorteo", acción de sortear, y "suerte", resultado de un sorteo, "lote", "parte". Derivadamente significa también "porción de terreno", porque la tierra colonizable de una comunidad se asignaba mediante un sorteo. Y dado que la posesión de terrenos y su legación era muy importante en el patrimonio familiar, tomará también el sentido de "heredad" y "herencia". El concepto es muy empleado en la teología anticotestamentaria, y los LXX podrán verterlo profusamente en la palabra kléros y sus derivados. Canaán es la "herencia" de Israel (Ex 6,8), Yahvé "distribuye" la tierra prometida entre las tribus de Israel (Num 26,52ss) y Leví recibe como "heredad" el servicio de Dios (Dt 10,9), Israel es la "parte" elegida por Dios de entre las naciones (Dt 32,9), Dios "repartirá" a cada uno según sus obras (Dan 12,13), etc. En el Nuevo Testamento la herencia es el Reino (Col 1,12) y los cristianos herederos y coherederos con Cristo de las promesas (Rom 8,17) ${ }^{11}$.

Lo que aquí nos interesa resaltar es que en la teología neotestamentaria todos los cristianos sin distinción son kléros (1Pe 5,3), parte elegida por el Señor (Ef 1,11), herederos de la salvación (Gal 3,29). Si la tribu de Leví y los sacerdotes tenían al Señor como lote especial, en el Nuevo Testamento esto es referido a la totalidad del pueblo cristiano. Todos le tienen como heredad especial, todos son sacerdotes.

10. Cf. A. FAIVRe, o.c., 63-85, con excelente exposición y citas.

11. Para todo ello cf. W. FOERSTER, Kléros, en Theologisches Wörterbuch zum Neuen Testament III, 757-767 y 776-786. 
En el siglo III reaparece la palabra kléros, pero ahora referida sólo a una parte de los cristianos. ¿Qué ha ocurrido? La comparación de los ministros cristianos con la jerarquía veterotestamentaria ha operado el cambio. Lo hemos visto ya sugerido en la Carta de Clemente, que recordaba que los laicos se distinguían de sacerdotes y levitas y lo aplicaba a la Iglesia. Esta comparación, llevada más lejos, propondrá el paralelismo sumo sacerdote-sacerdote-levita y obispo-presbítero-diácono ${ }^{12}$. La jerarquía del Antiguo Testamento es entendida como figura de la jerarquía cristiana. Del mismo modo que la tribu de Leví tenía como kléros particular el servicio del Señor en vez de posesiones terrenas, y el resto de las tribus les asistía con el diezmo, así sucederá con los neolevitas cristianos, los ministros ordenados: serán kléros especial del Señor, el clero. Los fieles les proveerán también en sus necesidades materiales para que puedan dedicarse sobre todo al servicio divino. Pero la cuestión no es sufragar la subsistencia de los ministros, sino la aceptación de una clase jerárquico-sacerdotal diferenciada del resto del pueblo. Esta noción paleotestamentaria de kléros "especial", dentro del kléros genérico que era todo el pueblo, fue anulada por el Nuevo Testamento, pero recobrada posteriormente por la teología cristiana. La transformación consistió en integrar dentro del pueblo cristiano, todo él kléros en el Nuevo Testamento, una parte o clero especial, con especial sacralidad y autoridad, siguiendo el modelo del Antigo Testamento.

La Tradición Apostólica, escrito canónico-litúrgico de inicios del siglo III atribuido a Hipólito de Roma, intenta matizar la palabra clero, y por oposición el significado de laico ${ }^{13}$. La palabra kléros no parece estar del todo fijada, aunque ya es muy clara. La Tradición Apostólica la utiliza en general en el sentido de "cargo eclesial" (TA $3 ; 8 ; 9 ; 10 ; 30$ ), un encargo oficial que la iglesia entrega a una persona para cubrir importantes responsabilidades internas. Pero a veces parece sinónimo de "sacerdocio" (TA 8). Pertenecen al clero el obispo, los presbíteros y los diáconos, de los que se dice que son "ordenados", se les imponen las manos, es decir, reciben un encargo solemne por parte de la iglesia (TA $2 ; 7 ; 8$ ). Los otros ministerios no son "ordenados", no hay imposición de manos, sino que son "instituidos" (confesores, viudas, lectores, TA 9; 10; 11) o "nominados" (subdiáconos, TA 13). A las

12. Origenes, In Iosue hom. 17,3; Cipriano, Epist. 1,1; Didaché 13,3 ya había comparado a los profetas, antiguos ministros cristianos, con los sacerdotes.

13. Dada la dificultad de la reconstrucción textual nos podemos fiar relativamente de las palabras, aunque en nuestro caso parece más claro. Cf. la introducción y notas de B. Botte a Hippolyte de Rome, La Tradition Apostolique (Sources Chretiennes 11), Paris 1968. 
vírgenes "no se impondrá la mano, pues sólo su decisión la hace virgen" (TA 12), como tampoco a quien diga poseer el carisma de curación, porque "los hechos mismos mostrarán si dice la verdad" (TA 14). Por otra parte, dentro del clero, el diácono "no está ordenado para el sacerdocio, sino para el servicio del obispo" (TA 8). El lenguaje sacerdotal se acentúa particularmente a propósito del obispo, al que se llama sumo sacerdote (TA 2-3; 8; 34). El clero es indirectamente definido en la Tradición Apostólica, hablando de las viudas, como quien "ofrece la oblación y tiene servicio litúrgico", pues "la ordenación se hace para los clérigos en vista del servicio litúrgico" (TA 10). La función específica del clero se liga al servicio cúltico, particularmente a la Eucaristía ("oblación"), aparte de la organización de la vida comunitaria14. Por lo que respecta a los laicos no se dice mucho, éstos son simplemente los demás, los que no son clérigos (TA 19;28).

Desde el siglo III, por tanto, posiblemente ya antes, nos encontramos con la existencia dentro de la Iglesia de dos clases de cristianos bien diferenciadas. Por una parte el clero, compuesto en principio por obispos, presbíteros y diáconos, y ampliado posteriormente. El obispo es la máxima autoridad en cada iglesia, y los presbíteros y diáconos le ayudan en la dirección de la vida y culto comunitarios. De otra parte el laicado, que componen el resto de cristianos. El concepto de laico tiene tendencia, también etimológicamente según hemos visto, a ser definido negativamente: quien no pertenece a tal destacable categoría. Entre los cristianos son los no clérigos, los no sacerdotes. Dicho de otro modo, los que no tienen encargo de autoridad, los que no están especialmente consagrados. Ellos integran la masa anónima y simple de los creyentes. El significado de la palabra no ha cambiado nada en absoluto. Esta distinción intraeclesial se ha mantenido incólume hasta hoy. La historia posterior no hará sino ahondar las diferencias.

c) Dos “clases" en la Iglesia.

La Iglesia queda dividida a partir de entonces en dos estados, al parecer de forma irreversible ${ }^{15}$. El clero se irá ampliando de modo voluble, absor-

14. A propósito de organización eclesial, en la Tradición Apostólica se pide para el obispo en la oración de ordenación el "Espíritu de soberanía" (TA 3), para el presbítero el "Espíritu de consejo" (TA 7) y para el diácono el "Espíritu de celo" (TA 8), lo que indica su responsabilidad específica en la Iglesia.

15. Sobre este punto cf. A. FaIvre, Les laïcs aux origines de l'Église, 108-240; B.D. DuPUY, Laïc, en Catholicisme VI, París 1967, 1627-1637; Y. CONGAR, Laïc et laïcat, en Dictionnaire de spiritualité IX, París 1976, 79-105; J.A. EsTRADA, La identidad de los laicos, Madrid 1990, 109-187. 
biendo todas las funciones eclesiales, subdiáconos, acólitos, lectores, ostiarios... Su tarea se concentra en el servicio cúltico. A cambio reciben un estipendio de la comunidad. El obispo asume todo el poder en la iglesia, que en parte puede delegar en los clérigos, sobre todo presbíteros y diáconos. Distribuirá "los cargos"16 comunitarios, y también los bienes que donan los fieles entre clérigos y necesitados ${ }^{17}$. Laicos y clérigos se van a ir distinguiendo económicamente como los que dan y los que reciben. La legalización de la Iglesia en el imperio romano conllevará una serie de privilegios para el clero, entre otros económicos, como la exención de impuestos, con lo que aumentará esta diferencia. El clero será cada vez más una especie de clase acomodada, de vida segura.

En la Tradición Apostólica se pedía ya en la oración de ordenación del diácono, que por la dedicación ejemplar a su ministerio pudiera llegar a un "grado superior"18, presumiblemente el sacerdocio. Se vislumbra el posterior cursus clericalis, con el que la Iglesia intentó reglamentar el acceso a las máximas dignidades ministeriales, de modo que hubiera un tiempo de preparación y de prueba para ello. Pero los ministerios menores se convirtieron así en simples escalones hacia el sacerdocio, con escasa consistencia propia, dejando de ser verdaderos ministerios. Los laicos parecen estar al final del escalafón, o mejor, quedan totalmente fuera. Habrá un rito que marque y perpetúe el cambio de estado, la entrada en otro mundo, la tonsura. Otro signo distintivo será la vestimenta.

Naturalmente, en vista de su preparación, los clérigos irán asumiendo todas las posibles funciones eclesiales. La Iglesia va siendo sólo cosa de clérigos. A los laicos toca seguir las indicaciones del clero, además de pagar su dedicación ${ }^{19}$. Atrás queda su participación en la elección de los ministros ordenados, en las decisiones importantes que atañen a la comunidad, en la presentación y acompañamiento, padrinazgo, de los neocristianos, incluso en la difusión del evangelio, que se irá haciendo tarea de especialistas, clérigos y monjes. En la Iglesia unos dirigen, organizan, actúan. Los otros obedecen, se dejan llevar. La pasividad será otra de las características del laicado.

Culturalmente, la diferencia entre clero y laicado devendrá abismal. La posibilidad de educación, patrimonio de la Iglesia durante la Edad Media,

16. Tradición Apostólica 3.

17. Didascalia Apostolorum II,25,8.

18. Tradición Apostólica 8.

19. A. FAIVRE, o.c., 240, lo señala sarcásticamente: proveer a las necesidades de los ministros es la función "más constante y mejor compartida" de los laicos, "el verdadero ministerio de los laicos". 
quedará lógicamente reservada para los clérigos. Laico será sinónimo de iletrado y rudo. Cultura y lengua les separan del clero, con nefastas consecuencias en el culto, donde serán meros espectadores. Visto todo esto, no es de extrañar que el laicado, para los clérigos, sea un castigo, laica communione contemptus, la degradación del clérigo que haya cometido un fallo grave en su ministerio. Hoy se habla, por los mismos y otros motivos, de "reducción" al estado laical.

El surgimiento del monacato, en su origen un movimiento laical, e incluso anticlerical, que huía y rechazaba la riqueza y poder del clero, a la larga no hará sino agravar la diferencia. Su ascesis, vida austera y desprecio de privilegios les hizo santos y modélicos ante el pueblo. Así que, por un lado, la jerarquía eclesial acudirá a los monasterios para conseguir buenos clérigos y, al mismo tiempo, querrá adecuar el clero al modo de vida ejemplar de los monjes. La vida de perfección que suponía el monacato será propuesta para el clero. Por otra parte, la necesidad de los monasterios de un servicio litúrgico propio convertirá en presbíteros a algunos de sus monjes, y la exigencia de una labor pastoral entre la gente que se concentra alrededor de los conventos extenderá este hecho. El resultado es que monjes y clero se asocian paulatinamente. Ideal de santidad, distanciamiento del mundo, celibato, tonsura, hábito, les igualan entre sí al mismo tiempo que les separan de los laicos. Sigue habiendo dos tipos de cristianos. De un lado los perfectos y espirituales; de otro los carnales, mundanos o seglares.

A todo esto va añadido que la pronta sacerdotalización del ministerio episcopal y presbiteral abarca virtualmente a todo el clero restante, dado que se prepara para ser aceptado en dichas órdenes mayores. Y sacerdote significa consagrado, separado del pueblo y acercado a la esfera sacra de la divinidad, para hacer de mediador o pontífice entre Dios y los hombres, y por tanto revestido de una especial dignidad. La Escolástica divagará en torno a un cambio ontológico producido por la ordenación sacerdotal, que será el modo de explicar conceptualmente este plus de sacralidad. El sacerdote no es sólo para la comunidad, sino que "es" algo distinto en sí mismo. De un lado los consagrados, de otro los profanos. El triunfo de la reforma gregoriana sobre el problema de las investiduras, visto como injerencia laical, parece haberse vuelto contra la misma Iglesia al dejar sentado que de las cosas de la Iglesia deben ocuparse los clérigos mientras los laicos se dedicarían a las cosas temporales. Y el protestantismo, con su rechazo virulento de toda distinción sacerdotal entre cristianos, sólo conseguirá que en el catolicismo se afiancen las barreras.

Muchas cosas han propiciado la distancia existente de clase y condición entre clero y laicos. Además, no solamente habría dos estados en la Iglesia, 
sino que uno es claramente superior al otro. El recelo de la teología cristiana hacia el matrimonio, característica del laicado, la distinción de Iglesia docente e Iglesia discente, la consideración de la Iglesia como sociedad desigual, son otros ejemplos de ello. La inferiorización del laicado pesa dos milenios.

En nuestro siglo se ha intentado una promoción de los laicos. La creación de la "Acción Católica" quiso estimular la participación de los laicos en el apostolado eclesial, y la de los "Institutos Seculares" pretendía integrar a los laicos en el ideal de perfección de los religiosos. Se ha buscado elaborar una teología propia del laicado ${ }^{20}$, y una definición positiva del ser laico. El concilio Vaticano II, por su parte, ha dedicado un amplio espacio a los laicos. Entre otras cosas, un decreto sobre su apostolado, Apostolicam Actuositatem; ha resaltado el sacerdocio común de los laicos, destacado su condición de pueblo de Dios como base previa a toda distinción ministerial, e intentado una definición del laico no dependiente del clero. Tras el Vaticano II la repetida perogrullada de que la Iglesia somos todos sólo ha buscado contrarrestar un retraso de siglos.

\section{3.- Teología del laicado.}

El concepto de laico ha mantenido inalterada su significación original en la Iglesia cristiana, que simplemente lo ha acomodado a su realidad. Laico es el no-clérigo. Dicho de otro modo, quien no tiene un encargo cúltico y organizativo en la Iglesia, ni la consagración y autoridad específicas que ello implica.

Supuesto esto, no debe existir una teología del laicado. La mejor teología del laicado será la que se autodisuelva en una teología de la vida cristiana. Una teología del laicado no es solamente superflua, es contraproducente, negativa. No puede haber una teología de los que no mandan, una teología de los no consagrados. Esto se opone a la esencia, si puede decirse así, de la Iglesia.

\section{a) Sacerdocio y cristianismo.}

La distinción entre clérigos y laicos tiene una larga tradición en la Iglesia. Existe posiblemente desde el siglo II, prácticamente desde su origen. Pero, parafraseando el dicho evangélico, al principio no era así.

Tal vez, el aspecto que más ha contribuido a la distinción haya sido la sacerdotalización del ministerio cristiano. Sacerdocio se emparenta con

20. Aquí hay que destacar a Y. CongAR, Jalons pour une théologie du laïcat, París 1953. 
sacralidad, y sagrado significa separado. Algo consagrado es algo entresacado de su situación en el mundo para acercarlo a la divinidad. Sacro es lo divino o divinizado, extraído y purificado de su mundanidad, hecho digno de la proximidad divina. Se consagran, mediante ritos purificatorios, personas, animales y cosas dedicadas al culto. Lo sagrado se opone a lo mundano. El sacerdote es la persona consagrada, separada del ambiente profano y avecinada a la irradiación divina. Podrá así presentarse ante Dios e interceder por el pueblo ofreciendo sacrificios que le granjeen su favor. Hace de intermediario y puente que salva la distancia entre Dios y el hombre pecador. De esta concepción, típica de todas las religiones, participaba también la religión israelita ${ }^{21}$. Arranca de la conciencia religiosa de la transcendencia de Dios y de la necesidad humana de conciliación con él. Pero con ello se realzaba también la figura del sacerdote, se le confería una especial autoridad y dignidad, que le elevaba por encima de los demás hombres, le podía llevar a monopolizar la concesión de las gracias divinas, como si fuera el único acceso a Dios. La primitiva Iglesia cristiana rechazó esta institución sacerdotal.

Jesús, en el origen del movimiento cristiano, no era sacerdote y su vida se vio envuelta en polémicas con los sacerdotes judíos. Sus críticas a la Ley y al culto (Mc 12,33), sus palabras sobre la indiscriminada cercanía y amor de Dios (Mt 5,45) suponían una relativización del sacerdocio. Por otra parte, en los relatos de la pasión los sumos sacerdotes aparecen como los máximos adversarios de Jesús (Mc 14,1; 15,10s). Tras su muerte se opondrán y perseguirán también a la naciente comunidad cristiana (Hch 4,1-3; 9,1s). La institución sacerdotal y el movimiento cristiano parecen haber elegido caminos diferentes.

Las primeras comunidades cristianas no conocieron la existencia de un sacerdocio individual entre sus miembros. Testimonio de ello es el Nuevo Testamento. En estas comunidades existen desde el principio ministerios de gobierno, de exhortación litúrgica, de enseñanża religiosa (1Cor 12,28; $1 \mathrm{Pe}$ $5,1 \mathrm{~s})$ pero tales ministros nunca son llamados sacerdotes 22 . En realidad no existen, sino que por el contrario, todos los cristianos son sacerdotes. Las únicas veces que el Nuevo Testamento utiliza la palabra sacerdocio dentro de las comunidades cristianas es para referirla, o bien a todos (1Pedro y Apocalipsis), o bien a Cristo (Hebreos) ${ }^{23}$.

21. A. VANHOYE, Sacerdotes antiguos, sacerdote nuevo, Salamanca 1984, 17-74.

22. J. DeloRme (ed.), El ministerio y los ministerios según el Nuevo Testamento, Madrid 1975. Exhaustivo análisis exegético y teológico sobre la ministerialidad neotestamentaria.

23. A. VANHOYE, o.c., que estudia extensamente la teología sacerdotal de Hebreos (pp. 81-246) y de modo más sucinto la de 1Pedro y Apocalipsis (pp. 251-316). 
Según la teología del Nuevo Testamento todos los cristianos son igualmente sacerdotes (1Pe 2,5.9; Ap 1,6; 5,10;20,6), como todos son clero y heredad de Dios, todos son santos (Flp 1,1 y otros encabezamientos de las cartas paulinas), elegidos (Ef 1,4.11), llamados (1Cor 1,9; Rom 1,6). Si todos son sacerdotes, todos tienen, a través de Jesucristo, acceso inmediato a Dios (aspecto destacado en Apocalipsis), poseen las primicias del Espíritu (Rom 8,23 ), son ciudadanos del cielo (Flp 3,20), están salvados por la gracia (Ef 2,5.8). Por otro lado, todos serán mediadores, anunciadores de Dios ante los no creyentes (lo que resalta 1Pedro), templo viviente de Dios (1Cor 3,16$)$ cuyo sacrificio sacerdotal será su propia vida entregada a los demás (Flp 2,17). Se utiliza, por tanto, el lenguaje sacerdotal como metáfora y expresión plástica de lo que significa ser cristiano. Por su parte, la carta a los Hebreos señala a Cristo como único y supremo sacerdote (Heb 4,14s) para indicar que en él acaba, siendo superado, el sacerdocio del Antiguo Testamento (Heb 7,18). La función sacerdotal, reconciliar con Díos, ha sido realizada de modo perfecto $\mathrm{y}$ definitivo, "de una vez para siempre" (Heb 7,27), en Cristo. A través de él la comunidad creyente puede llamarse sacerdotal, los fieles están santificados por la ofrenda de Cristo $(9,14)$, "pueden entrar en el santuario" $(10,19)$, ofrecer sacrificios $(13,15 \mathrm{~s})$, rendir a Dios "un culto que le sea grato" $(12,28)$.

El cristianismo supuso una ruptura con la antigua institución sacerdotal. Ya no es necesaria. Cristo, y en él todos los cristianos, asumen sus características. Todos son acercados a Dios, salvados, santificados, reconciliados, mediante la fe en Cristo como sola condición. Todos serán mediadores ante los demás, mediante su vida y palabra, de la salvación que Dios ofrece. En Cristo se colma definitivamente la distancia entre Dios y el hombre, su sacrificio hace inútiles todos los demás. Esta es la razón teológica de la ruptura. Ello se une al resquemor cristiano ante la autoridad, particularmente la de los sacerdotes.

Pero pronto se olvidó esta innovación cristiana respecto al Antiguo Testamento. La continuidad, también obvia, entre el Antiguo y Nuevo Testamento prevaleció sobre la ruptura inicial que este aspecto suponía, diluyéndola. Se fue asociando, remitiéndose al Antiguo Testamento, jerarquía levítica y jerarquía eclesial, fijada a lo largo del siglo II en la tríada obispo, presbítero y diácono. Paralelamente se aceptaba en la Iglesia la existencia de un clero especial y su contrapunto laico. Al obispo, en primer lugar, le será aplicado de modo habitual el título de sacerdote debido a su protagonismo cúltico: presidencia de la eucaristía, del bautismo, de la ordenación sacerdotal, poder de perdonar los pecados ${ }^{24}$. La consideración de la eucaristía como

24. Hipolito, Tradición Apostólica 3; 7; 8; IGNACio dE AnTIOQUíA, A los Esmirniotas $8,1 \mathrm{~s}$. Sobre todo esto J. MoINGT, Caractère et ministère sacerdotal: "Recherches de Science 
sacrificio reforzaba esta idea y la función episcopal como autoridad religiosa casaba también con ello. La misma calificación se podía dar a los presbíteros, que rodeaban al obispo en la celebración eucarística y eran sus ayudantes en el gobierno de la iglesia ${ }^{25}$. La expansión de la Iglesia, sobre todo en las zonas rurales, a partir de su reconocimiento por el imperio, llevó a los presbíteros a dejar el consejo presbiteral y diseminarse por las nuevas comunidades. Allí representaban el papel de los obispos, asumiendo casi todas sus funciones, aunque dependiendo siempre de su obispo. El presbítero se fue convirtiendo en el verdadero "sacerdote", como le denominamos hoy, mientras la figura del obispo se centraba más en tareas de dirección y administración.

Los nuevos sacerdotes, a ejemplo de los antiguos, recuperaban cierta exclusividad en el culto, su dedicación principal, y para ello una consagración o cercanía especial a Dios, a expensas del resto de cristianos, que las perdían. Sin duda que se sigue hablando del sacerdocio común a todos los cristianos cuando se establece un sacerdocio jerárquico ${ }^{26}$, pero la expresión se vacía de contenido. Si lo típico del sacerdocio es la consagración, una consagración "especial” y "superior" siempre eliminará una consagración "común".

La teología escolástica, buscando la esencia de las cosas a ejemplo de la filosofía griega, conceptualizó ontológicamente esta diferencia de sacerdocio. La esencia de una cosa sería aquello que tal cosa posee exclusivamente, que la identifica consigo misma y la distingue de todas las demás. La esencia del sacerdocio presbiteral, lo que nunca le puede faltar y no se da fuera de él, es el poder de consagrar la eucaristía, en realidad poder de Orden o poder sacramental concentrado en la transustanciación eucarística como su más alta expresión. De ahí las dudas de la Escolástica sobre la sacramentalidad del episcopado, que sólo añadía al presbiterado un poder de jurisdicción. Este poder de Orden, que competía solamente al sacerdote, le distinguía ontológicamente, en su esencia, de los no sacerdotes. La ordenación confería a una persona unos poderes superiores, sagrados, que le elevaban y

Religieuse" 56 (1968) 563-589; B. SESBOÜÉ, Ministerio y sacerdocio, en El ministerio y los ministerios según el Nuevo Testamento, Madrid 1975, 437-446; A. LEMAIRE, Les ministères dans l'église, París 1974, 55-74.

25. Ignacio de Antioquia, $A$ los Efesios 4,1; Hipolito, Tradición Apostólica, 4; 7; CIPRIANO, Epist 61,3, puede concluir: "Los presbíteros están unidos al obispo por la dignidad sacerdotal".

26. Por ejemplo Tertuliano, De exh. cast. 7: "Aunque laicos, ¿no somos también nosotros sacerdotes? Está escrito: ha hecho de nosotros un reino de sacerdotes para Dios su Padre". 
dignificaban para realizarlos 27 . Toda la argumentación descansa en el realce dado a la consagración eucarística y al poder de realizarla. Tal concepción sublimaba de modo abrumador y sacral la figura del sacerdote. Pero se equilibra bastante con sólo pensar que la eucaristía es, como todo sacramento, una acción eclesial-comunitaria, que realiza la iglesia para formar la iglesia, y que la consagración es una de sus partes, pero no el todo.

La sacerdotalización de los ministros de la Iglesia ha supuesto una reducción de sus tareas, que no son sólo cúlticas. Así se reconoce en el Vaticano II cuando al lado del munus sacerdotal se insiste en el profético y el regal (LG 25-28; PO 4-6). La función del ministerio ordenado no se agota en el aspecto sacramental, ni éste debe absorber su oficio pastoral y de enseñanza. Tal sacerdotalización abrió también una gran brecha entre los sacerdotes y quienes no lo eran, contraria a la teología novotestamentaria, que desechaba una distinción basada en lo sagrado. Según esto, no se debería admitir en la Iglesia la existencia de un sacerdocio especial. El ministerio ordenado cristiano es algo distinto. Es una institución imprescindible en la Iglesia, que ha existido desde siempre dentro de ella, aunque no se llamaran siempre obispos o presbíteros, sino apóstoles, pastores, profetas... Si su carisma era el de presidencia, para resumirlo en una palabra, su función le llevaría a presidir también la liturgia comunitaria, como de hecho ha ocurrido históricamente ${ }^{28}$. Parecerá entonces que asume tareas sacerdotales, preside el culto como los antiguos sacerdotes, pero será ésta la única analogía. Y sólo en este sentido se podrá hablar de su munus sacerdotale. Pero no es sacerdote por encima del común sacerdocio cristiano, no posee una mayor sacralidad, no es ontológicamente distinto de la igual dignidad del ser cristiano.

\section{b) La autoridad en la Iglesia primitiva.}

La otra característica que quiere diferenciar el clero del laicado es la autoridad que corresponde a aquél. Pero la idea de autoridad siempre ha sido muy problemática en la Iglesia. El Nuevo Testamento recela de ella, con la excepción de las Pastorales ${ }^{29}$. Y la teología ha repetido hasta la ofuscación, por la contradicción inherente que implica, que la autoridad en la Iglesia es un servicio.

27. S. DiAnICH, Teologia del ministero ordinato, Roma 1984, 38-41.

28. A. Lemaire, o.c., $44 \mathrm{~s}$.

29. Las llamadas cartas Pastorales vieron en la autoridad el único medio de mantener la supervivenciade la Iglesia ante la invasión de ideas gnósticas que hacían peligrar la fe original cristiana. Cf. R. BRown, Las iglesias que los apóstoles nos dejaron, Bilbao 1986, 31-45. 
Los sinópticos nos presentan un Jesús crítico e irónico hacia la autoridad, opuesto a ella. "Sabéis que los que son tenidos como jefes de las naciones, las dominan como señores absolutos y sus grandes las oprimen con su poder" (Mc 10,42 par). Una de las tentaciones que debió rechazar, o más bien las tres puesto que coinciden en ello, es la del poder (Mt 4,1-11; cf. también Jn 6,15). La comunidad que quiere formar no debe llamar a nadie "maestro", ni "padre", ni "preceptor" (Mt 23,8-10), esto es, jefes, sino que debe ser una comunidad de "hermanos", de iguales, una comunidad sin estructuras de poder ${ }^{30}$. Reitera a sus discípulos que sean como niños, como los que nada pueden (Mt 18,3; Mc 10,14s). Que el que quiera ser el primero sea el servidor de los demás, poniéndose a sí mismo como ejemplo (Mc 10,43-45; Jn 13,14ss). Llama bienaventurados a los pobres -en este caso tanto da que sean "de espíritu" (Mt 5,3) o a secas (Lc 6,20)- y, en fin, su vida fue una protesta contra toda marginación y una defensa de los sin-poder. Confiar en el reino de Dios es descreer del reinado humano.

Todo esto no podía sino calar profundamente en la primitiva iglesia. Los cristianos se autodenominan entre sí sobre todo como "hermanos" (Rom 7,4; Mt 18,15; 1Jn 2,9ss). Para designar a sus dirigentes tienen buen cuidado en evitar la terminología de la sociedad, pues evocaría autoritarismos. Por el contrario, emplean una terminología que resalta la idea de diaconía, ministerio, esto es, servidumbre, esclavitud ${ }^{31}$. El problema es que toda comunidad, por definición, necesita una normatividad interna, uno de cuyos aspectos es la autoridad, y la Iglesia no puede sustraerse a esto. La única solución es entender la autoridad como un "carisma", esto es, un don que se utiliza para la edificación de la comunidad (1Cor 12,$7 ; 14,26)$, un servicio en el sentido más literal.

¿Cómo hacer esto realidad, evitar que se quede en palabras? Los términos "autoridad" y "servidumbre", ¿pueden darse juntos? ¿No son tan opuestos que uno de ellos debe por fuerza desaparecer, engullido por el otro? Por una parte, el mensaje cristiano relativiza la autoridad. Por otra, la Iglesia es una comunidad humana, y la precisa. Así que no hay más remedio que vivir en esa dialéctica imposible. De todos modos, queda claro que la Iglesia no podrá ser una comunidad en la que el aspecto de autoridad sirva para diferenciar a sus miembros. No puede componerse de los que mandan y los que no mandan. Sus instituciones deberán buscar mitigar el deslizamiento hacia el exceso que toda autoridad acarrea. Por ejemplo, eliminando la

30. G. LOHFink, La Iglesia que Jesús quería, Bilbao 86, 55-60.

31. J. Delorme, Diversidad y unidad de los ministerios según el Nuevo Testamento, en El ministerio y los ministerios según el Nuevo Testamento, 288-299. 
distinción entre clérigos y laicos. De manera que los dos aspectos que más han servido para caracterizar el clero frente al laicado, consagración y autoridad, son los que ha querido rehuir la Iglesia primitiva, remitiéndose a Jesús.

\section{c) Definición de laico.}

No hay ninguna razón, por tanto, para una división de la Iglesia en clérigos y laicos. Al contrario, esta diferencia socava algo esencial y propio de la Iglesia cristiana. Las consecuencias, como hemos visto, han sido negativas para la comunidad nueva que pretendía ser. Y lo siguen siendo. Se desemboca siempre en una sobreactividad de los clérigos y, correspondientemente, en una pasividad de los laicos. Por eso las palabras laico y clérigo, y la realidad que indican, deberían desaparecer ${ }^{32}$. Suponen una denominación estructural de la comunidad cristiana y una clasificación interna centrada en la autoridad y sacralidad, lo que choca con el hecho cristiano original. Lo mismo hay que decir de la palabra "seglar", mundano.

Suele proponerse como alternativa a clero-laicado la distinción comunidad-ministerios ${ }^{33}$-quizás sería mejor comunidad-carismas si ministerio se emplea en el sentido restringido de encargo oficial de la Iglesia-. Partiendo y apoyándose en la comunidad se crean diversos ministerios y carismas que revierten en ella, que la construyen. Estos ministerios no serán dignidades o títulos sino, siguiendo su propio nombre, servicios. Desarrollada una teología del ser cristiano, la condición común y principal de los miembros de la Iglesia, podrán definirse a partir de ella sus distintos ministerios. Sin embargo, y volviendo a los términos que solemos emplear, en la cuestión de los laicos se ha procedido al revés. Se ha pretendido definir el laico, el ser común cristiano, partiendo del clero, ministerio especial en la Iglesia. Es como definir el todo desde la parte. Se descentra lo que se quiere delimitar. Como de ahí resultaba una definición negativa, se ha buscado afanosamente una determinación "positiva" del laico, que fuera más allá del mero ser no-clérigo. Sobre esto hay que decir que toda definición del laico acabará o en una tautología, coincide con el ser cristiano, o en una negación. La misma palabra laico se opone a una concreción clara. Si laico es quien pertenece a la

32.. Cf. R. PARent, Una Iglesia de bautizados, Santander 1987, que aboga también por la eliminación terminológica de clero y laicado, haciendo responsable a, esta diferencia de rango, y con razón, de todos los males del funcionamiento comunitario de la Iglesia.

33 Por ejemplo Y. CONGAR, Ministerios y comunión eclesial, Madrid 1973; B. ForTE, Laicado y laicidad, Salamanca 1987; J.I. GonZALEZ FAus, Hombres de la comunidad, Santander 1989. 
masa indefinida y anónima, mal se le podrá definir. Además, la idea de laico encierra una negación conceptual, quien no sobresale, quien se pierde en el pueblo. La búsqueda de una definición positiva del laico ha llevado así a soluciones fantasmales. El Vaticano II, recogiendo los intentos de la incipiente teología del laicado, será una muestra de ello.

El número 31 de la Lumen Gentium aborda la definición del laico. Laicos son "todos los fieles cristianos, a excepción de los miembros del orden sagrado y los del estado religioso", que participan del triple oficio de Cristo y "ejercen en la Iglesia y en el mundo la misión de todo el pueblo cristiano". Hasta aquí estamos en lo tautológico y negativo. Cuando a continuación se quiere precisar lo que caracteriza positivamente al laico se dice que "el carácter secular es propio y peculiar de los laicos" y que corresponde a los laicos "tratar de obtener el reino de Dios gestionando los asuntos temporales", pues "viven en el siglo, en todos y cada uno de los deberes y ocupaciones del mundo", vida familiar y profesión social. Su misión es la "santificación del mundo desde dentro (...), iluminar y ordenar las realidades temporales, a las que están estrechamente vinculados".

Según esto, lo "secular" y "temporal" es lo propio del laico. El concilio ha defendido, y es una de sus innovaciones, el valor y la autonomía de lo temporal (GS 36). En principio, no se está hablando del mundo en sentido negativo. En principio, pero cierta negatividad es inevitable. Si se destaca la índole secular como "propia" del laico, esto sólo puede ser porque el clero y los religiosos, los que no son laicos, se distinguen de ellos por su separación del mundo, en definitiva por su sacralidad. Ineludiblemente se mantiene la vieja dicotomía temporal-profanớ-laico y espiritual-sagrado-clero y religiosos $^{34}$. Y si no se quiere postular una consagración especial del clero y los religiosos, será difícil entender la idea de que éstos no viven en el "mundo", como los laicos, obviamente en sentido literal, pero también en sentido teológico، Poseer el carisma institucional -aunque suene contradictorio- de presidencia, institucionalizado por su importancia para la Iglesia, que es lo propio del ministerio ordenado, les carga con una especial dedicación, tal vez

34. G. PHILIPS, La Iglesia y su misterio en el concilio Vaticano II, Barcelona 1969, II, 27, así lo nota en su comentario a este texto: "Los sacerdotes están ante todo consagrados al servicio de la liturgia y de la pastoral, en virtud de una vocación particular y a modo de ministerio permanente (...). Esta es la razón por la que la promoción temporal no tiene la misma importancia para el sacerdote que para el simple fiel". No puede evitar oponer lo temporal (profano) a lo litúrgico (sagrado) y pastoral. A esto hay que decir que lo litúrgico-sagrado no es propio de los ministros, sino sólo su presidencia. Lo pastoral sí es propio de los ministros, pero esto no se opone a lo temporal, sino todo lo contrario. Por otra parte, el concilio distinguió a los religiosos no clérigos de los laicos, contrariamente a lo que se hacía antes, precisamente porque no comparten la vida secular de los laicos. 
exclusiva, a la comunidad, pero en modo alguno les exime de los problemas del mundo, políticos y sociales, antes al contrario, en ellos se deben inmèrger para mejor compartir y entender la realidad de la iglesia que tienen a su cuidado. Y lo mismo hay que decir de los religiosos, que para predicar el reino se integran en el mundo de modo particular, como fuerza de choque y contraste que critica la raíz de sus males, pretendiendo ser así vanguardia de la Iglesia 35 .

Cuando el concilio concreta lo que supone la índole secular del laico habla de la "vida familiar y social", y "oficios y actividades del mundo", cosas que no son necesariamente una exclusiva de los laicos, como lo muestra la existencia de clero casado de rito oriental y la experiencia de los sacerdotes obreros, por ejemplo. Que los ministros de la Iglesia deban renunciar a llevar directamente asuntos políticos y sociales, es más una exigencia interna de su tarea, que para aceptar el pluralismo de su comunidad no se identifica públicamente con concretas opciones, que una separación del mundo.

Sobre el apostolado de los laicos se dice que "están especialmente llamados a hacer presente y operante la Iglesia en aquellos lugares y circunstancias en los que ella no puede ser sal de la tierra sino a través de ellos" (LG 33b). La frase es superflua y lleva a confusión. Los laicos son necesarios donde la Iglesia no puede llegar sino por ellos. ¿Son menos necesarios donde "la Iglesia” pueda hacerse presente sin ellos? ¿De qué Iglesia se está hablando? Se sigue expresando lo temporal como lugar propio de la actividad de los laicos. En ese ámbito el clero, dado que está al margen de lo profano, no puede insertar la Iglesia, y de ahí la contribución imprescindible del laicado ${ }^{36}$. Asoma la inveterada tradición de que la Iglesia es para los clérigos y el mundo para los laicos. Está claro, sirr embargo, como dice el concilio un poco antes, que los laicos, en cuanto iglesia que son, "participan en la misma misión salvífica de la Iglesia" (LG 33b). Esta participación genérica no debería, pues, ser considerada extraordinaria, sino natural. Pero su catalogación

35. Cf. D. NATAL, Pequeña antropología de los votos: "Estudio Agustiniano" 18 (1983) 177-233.

36. G. PHILIPS, o.c., 41, lo confirma de nuevo: "a los seglares incumbe hacer efectiva, allí donde están, la presencia de la Iglesia, allí donde, sin ellos, la Iglesia no hallaría medio de cumplir su misión. En otros términos: el clero solo no puede establecer todos los contactos indispensables a la Iglesia para cumplir su obra de testimonio y de sacramento de salvación. La acción a distancia no es fácil de llevar a cabo. Pero el clero, por el hecho mismo de su vocación, tendrá siempre que vivir un poco retirado de la vida profana, aunque su separación del siglo sea menos severa que la de los religiosos. Hay que admitir, pues, que incluso en el supuesto de que cumpla escrupulosamente su deber, el clero no podría asegurar totalmente la misión de la Iglesia". 
de laicos les arrincona en lo temporal, como si los asuntos internos de la Iglesia no fueran con ellos. Su actividad en tareas eclesiales parece una concesión de la Jerarquía (Cf. LG 33c).

Lo temporal no es una cuestión que pueda separar a cristianos y ministros ordenados, aunque cada uno lo viva, en razón de su ministerio y carisma, de modo diferente. Paralelamente, tampoco les separa lo eclesial, la construcción de la comunidad, en la que todos participan igualmente, aunque de nuevo, y por lo mismo, vivido de distinta manera ${ }^{37}$. $Y$, en fin, la misión de la Iglesia es el mundo, y no puede sino inmiscuirse en él, aunque lo critique, lo que debe hacer por su fe, y en este sentido, se distancie de él, le suponga un contraste ${ }^{38}$.

Ultimamente A. Faivre ${ }^{39}$ ha presentado una definición distinta de laico, que coincidiría con los que denominamos hoy "cristianos comprometidos". Se remite a Pío XII que, en su impulso de la Acción Católica, distinguió laicos y fieles de ese modo ${ }^{40}$. Según Faivre, el laicado como estructura eclesial apareció en el siglo III y no antes, aunque parezca una eclosión brusca. Apoyado en algunos textos de esta época ${ }^{41}$ sobre el rigorismo matrimonial que asociaba una mayor perfección a la monogamia absoluta, concluye que los laicos serían el grupo de cristianos "hombres de una sola mujer" (1Tim 3,2.12; Tit 1,6), que así podrían ser un vivero para el sacerdocio jerárquico. Serían bautizados, no clérigos, de especial ejemplaridad. Este laicado como grupo selecto de cristianos tendría una existencia corta, y en el siglo IV laico es simplemente sinónimo de fiel no clérigo. Basado en esto, rechaza la identificación que hoy se hace entre laico y fiel. La "teología del laicado no puede confundirse con la teología del pueblo de Dios", pues el laicado "postula necesariamente una dicotomía dentro de este pueblo", que excluye al clero pero no engloba a todos los cristianos. Los laicos serían así una especie

37. Por eso no se entiende la advertencia que se hace a los laicos en la Christifideles Laici 2 contra "la tentación de reservar un interés tan marcado por los servicios y las tareas eclesiales, de tal modo que frecuentemente se ha llegado a una práctica dejación de sus responsabilidades específicas en el mundo profesional, social, económico, cultural y político". O mejor dicho, se entiende desde la, al parecer, infranqueable barrera entre clérigos y laicos.

38. G. LoHFINK, La Iglesia que Jesús quería, Bilbao 1986. Toda la Iglesia será "sociedad de contraste" en el mundo por el seguimiento de su maestro. Así es como mostrará el reino en el mundo.

39. Cf. su ya citado libro Les laïcs aux origines de l'Église, París 1984.

40. Ibid., 8 .

41. Clemente Alejandrino, Stromata III 12,90; Tertuliano, De monogamia 11-12; Origenes, In Lc Hom. 17; concilio de Elvira, can. 38; ver A. FAIVRE, o.c., 73-82. 
de locomotora que tira del resto de fieles hacia las exigencias del cristianismo, que les recuerda lo que pueden y deben $\operatorname{ser}^{42}$.

La tesis de Faivre sobre los laicos enrevesa la ya negativa división clérico-laical entre cristianos. Distinguir estructuralmente a los cristianos que no forman parte del ministerio ordenado según su moralidad o compromiso tampoco parece muy buena idea. Faivre reconoce que los textos patrísticos que le sirven de fundamento no son definitivos para su hipótesis. La cita de Tertuliano, por ejemplo, declara su oposición a un grupo especial de este estilo ${ }^{43}$. Esto muestra que puede haber existido, por supuesto, pero también que no era aceptado universalmente. De todos modos, el mismo Faivre da la solución. La teología del laicado es "provisional", dice, aparece y desaparece en tiempos de crisis, sólo sirve para ayudar al cambio de modelo eclesiológi$\mathrm{CO}^{44}$.

Lo deseable sería que desapareciese definitivamente. Laico, y su antípoda clérigo, deben diluirse en el ser cristiano. A cada bautizado corresponderán, según sus capacidades y las necesidades de la Iglesia, diferentes carismas y ministerios que edifiquen la comunidad.

\section{4.- Funciones de los laicos.}

Las tareas de los laicos serían las de todo bautizado, que concretan la única misión de la Iglesia, de la que todos son responsables, realizada de distinto modo según el propio carisma y ministerio (LG 9; 33). Pero su destino de laicos, bien diferenciados de los clérigos, las ha empequeñecido. Las que se les reconocen quedan vaciadas debido a su estrecha dependencia del clero. Suele darse la paradoja de que lo que se les pide oficialmente les es al mismo tiempo obstaculizado, y desde la misma instancia. Su condición laical les hace meros espectadores de su realidad cristiana.

\section{a) Oficio sacerdotal.}

El sacerdocio cristiano, común a todos, es existencial más que cultual. El sacrificio que ofrecen a Dios, y que le es grato, es su propia vida vivida desde la primacía de Dios y el amor a los demás. Se saben así cercanos a Dios, son su templo y sus elegidos. Pero la Iglesia es una comunidad de fe, y en cuanto

42. Ibid., 248s.

43. De monogamia 11-12: "Si no se obliga a todos a contraer un único matrimonio, ¿dónde vamos a buscar, para hacerles entrar en el clero, personas casadas una sola vez? ¿Hará falta instituir un orden particular de personas casadas una sola vez entre las que elegir a los sacerdotes?". Cf. A. FAIVRE, o.c., 74.

44. Ibid., 249. 
tal, necesita una oración comunitaria que exprese y fortalezca al mismo tiempo su fe común, en la cual vive, espera, y de la que da testimonio. Necesita un culto externo y comunitario, una liturgia.

Los llamados laicos deberían participar activamente en este culto, como de hecho se les pide y es lógico, dado que es una acción de toda la iglesia que construye la iglesia. Pero la realidad es muy distinta. Durante mucho tiempo los laicos no han entendido la oración cristiana, quedando excluidos de ella. El concilio Vaticano II ha querido subsanar esto, pero la enmienda no es suficiente (LG 10-11; SC 48). Lo más que pueden hacer es escuchar activamente. Pero la mera escucha es más bien pasiva, o propicia irremediablemente la pasividad. La reglamentación litúrgica, insitiendo tanto en la diversidad de acción entre ministros y fieles, clero y laicos, no facilita lo que exige de los laicos, sino al contrario. El clero acumula en el culto un protagonismo excesivo, que reduce la participación de los laicos a la contemplación. Según solemos expresarnos, el sacerdote "dice" la misa, mientras el resto la "oye".

Esto sucede en todos los sacramentos. En el matrimonio es el sacerdote quien "casa", por más que la teología nos diga que son los esposos los ministros del sacramento. Cuando la penitencia y la unción de enfermos se realizan dentro de una liturgia comunitaria, lo que es de alabar, el clero parece absorver toda la acción sacramental, mientras los laicos escuchan y la reciben. Y lo mismo sucede con el bautismo, la confirmación y la ordenación. El principio sacral distanciador de clérigos y laicos es la causa de ello. Sin duda que a los ministros corresponde una tarea especial en la acción litúrgica, que es la de presidir ${ }^{45}$. Pero presidencia no significa exclusividad.

Una participación activa de los cristianos en el culto sólo puede conseguirse permitiendo una participación real, fomentada institucionalmente. El espacio que se les ha ido dando, por ejemplo en las lecturas, preces, a veces comentario a las lecturas, de la eucaristía, debería alargarse mucho más, abarcando otras partes de la liturgia eucarística (desde el saludo inicial a la despedida, pasando por la plegaria eucarística), y lo mismo en los demás sacramentos, de modo que la oración comunitaria de la iglesia llegue a serlo verdaderamente. Esto no menoscaba la función sacerdotal de los ministros, sino que les integra en la oración común. Se eliminaría así también la "soledad" del ministro en el culto cristiano.

45. Para la justificación teológico-litúrgica de ello cf. S. DiANICH, Teologia del ministero ordinato, 202-211. 
b) Oficio regal.

La función regal del laicado suele asociarse a la tarea de permear sus compromisos y responsabilidades sociales desde su fe. Esto es correcto, pero se descuida por completo su participación regal en la vida interna de la Iglesia, como si ello fuera solamente asunto del clero. Dado que una de las características atribuidas al clero era la de la autoridad, a los laicos no quedaba más que la obediencia. Pero la función de regir del ministerio ordenado, para ser fiel al cristianismo de los orígenes, no coincide con la de mandar, sino con la de servir. Su oficio regal habrá de concebirse siempre de un modo peculiar, como oficio pastoral. Su carisma de presidencia de la vida de la iglesia le convierte en punto de referencia de la fe de la comunidad. Esto es, sirve a la unidad de la iglesia a partir de la pluriformidad de sus miembros. Es signo, y estructura, de unidad. Su tarea cotidiana no será la de mandar, sino la de animar, coordinar, supervisar, respetando la diversidad de las expresiones de fe. Sólo en casos extraordinarios, cuando la diversidad eclesial amenace con llevar a la ruptura, será necesario el uso de la autoridad, precisamente para servir a la unidad de la iglesia. Pero, como queda dicho, esa no es su función ordinaria ${ }^{46}$.

La participación de los bautizados en la realeza de Cristo implica una corresponsabilidad de todos en la construcción de la Iglesia visible e institucional. Tal coparticipación de todos en la dirección de la Iglesia se realiza de modo distinto a tenor de los diversos carismas y ministerios. Pero, en cuanto común, es previa a la distinción, al mismo tiempo que su fundamento. Sólo así puede significar algo decir que la iglesia somos todos. La presencia de los laicos en las decisiones importantes de la comunidad no es una concesión del clero, sino consecuencia natural de su ser Iglesia. En realidad no es sino recuperar antiguas y casi olvidadas tradiciones.

Por ejemplo, la elección de los ministros de la iglesia. Los primeros siglos de la historia cristiana testimonian que el modo más común de elección de obispos incluía la participación activa de la comunidad ${ }^{47}$. Su prece-

46. Sobre esto S. DIANICH, o.c., 170-175 y 183-192, que además interpreta la enseñanza autoritativa del Magisterio dentro de este mismo marco; R. BROWN, Las iglesias que los apóstoles nos dejaron, 31-45 y 85-120, que entiende, como ya se ha visto, que el escoramiento hacia la autoridad de las cartas Pastorales fue el modo de preservar la unidad de la iglesia en una situación de crisis. De idéntica forma, pero al contrario, la carencia de este ministerio en la eclesiología juánica la inutilizó para evitar su desintegración cuando surgieron diferencias internas de interpretación doctrinal.

47. Ver sobre esto los números 77 y 157 que la revista Concilium dedica a este tema. Particularmente H.M. LEGRAND, Sentido teológico de las elecciones episcopales en la Iglesia antigua: "Concilium" 77 (1972) 44-56; y P. STOCKMEIER, La elección de obispos en la Iglesia antigua: "Concilium" 157 (1980) 8-18. 
dente estaba en la práctica de las iglesias neotestamentarias respecto a sus líderes"4. La continuación de ello se lee en Didaché 15,1: "Elegíos, pues, obispos y diáconos que sean dignos del Señor (...), que desempeñen para vosotros el ministerio de los profetas y los maestros". La Carta de Clemente, reconviniendo a los corintios por su actitud contra los presbíteros, argumenta que son "hombres establecidos por los apóstoles, o posteriormente por otros eximios varones con consentimiento de la iglesia entera"49. Es conocida la frase de la Tradición Apostólica, "se ordenará como obispo quien haya sido elegido por todo el pueblo"50. Cipriano, por su parte, a propósito de la elección de Cornelio como obispo de Roma, habla de un suffragium, voto, del pueblo; además del testimonio de los clérigos y la aprobación de los sacerdotes 51 .

La participación del pueblo en la elección del obispo, sea por elección directa, sea por consentimiento hacia alguien propuesto, lo que suponía también el rechazo, se fue restringiendo paulatinamente, con el punto de inflexión en el reconocimiento estatal a la Iglesia, pero nunca por razones teológicas, y de todos modos sin eliminarlo completamente. Razones políticas de diversa índole (importancia social del episcopado, problema de las investiduras, rivalidades internas en los cabildos) concentraron la elección en los obispos de la región eclesiástica, en el cabildo catedralicio y, finalmente, en el papa $^{52}$. Y como muestra de la pervivencia de la participación de los fieles en la elección del clero, aunque simbólica y más bien irreal, la pregunta a la asamblea sobre la aptitud del candidato en el actual ritual de ordenación.

Lo mismo hay que decir de la participación de toda la comunidad en las cuestiones internas, uno de cuyos aspectos es la elección de ministros. Constituye un uso natural en el cristianismo primitivo. Se percibe en las comunidades de Pablo (1Cor 5,4s; 6,1-5), en las de Mateo (Mt 18,15-17) y en otras iglesias neotestamentarias (Act 13,3 y 14,27; Sant 3,1; 1Jn 4,1; Heb 13,22). También la Carta de Clemente reconoce, con todo lo que ella significa, el acuerdo comunitario como modo de actuar ${ }^{53}$. La Tradición Apostólica supo-

48. Cf. el breve análisis de R. SCHNACKENBURG, La colaboración de la comunidad, por el consentimiento y la elección, según el Nuevo Testamento: "Concilium" 77 (1972) 18-30.

49. 1 Clem 44,3 .

50. Tradición Apostólica 2.

51. CipRIANo, Epist 55,8; cf. también Epist 67,5.

52. El canon 4 del concilio de Nicea (a. 325) pone la designación, en principio, en los obispos de la eparquía. Para el Decreto de Graciano (a. 1140) "la elección corresponde a los clérigos; el consentimiento al pueblo" (dist. 62). Sólo en este siglo, con la promulgación del Código de Derecho Canónico, la elección queda jurídicamente reservada al papa (can. 329,2: "El Romano Pontífice designa libremente a los obispos"), aunque de hecho ya se hacía desde el siglo XIII.

53. 1 Clem 54,$2 ; 63,2$. 
ne la deliberación de la comunidad a la hora de admitir al catecumenado a los que desean ser cristianos 54 . San Cipriano, por otro lado muy consciente de su autoridad episcopal, repite que no quiere tomar ninguna decisión en su iglesia sin consultar al clero y al pueblo55. La generalización de concilios regionales de obispos, expresión de cohesión entre las iglesias y eficaz arma contra las herejías, condujo, por contra, al arrumbamiento del pueblo en la toma de decisiones eclesiales, que sólo podrá ya aceptar. El gran crecimiento de la Iglesia, la consiguiente mayor estructuración y especialización de sus instituciones, irá reduciendo esta participación a la nada. Sínodos provinciales, concilios ecuménicos, sedes diocesana y romana, serán los centros de decisión.

Tras el concilio Vaticano II se ha querido revitalizar la presencia de los laicos en organismos diocesanos y parroquiales, pero ésta es excesivamente testimonial y supeditada al clero, como no podía ser de otro modo en razón de esta misma división. Pero el oficio regal de los cristianos, en cuanto común, exige, para ser real, la igual participación de todos en las instancias decisorias y administrativas de la Iglesia. La diversidad de funciones concretará el modo de esta participación sin eliminarla. De no ser así se les impide lo mismo que se les pide: su activa contribución a la construcción de la Iglesia.

\section{c) Oficio profético.}

Profetismo, en sentido teológico amplio, indica el testimonio de la voluntad de Dios en palabras y actos. Para los cristianos, testimoniar la propia fe es desde siempre una exigencia natural, que ha conformado la Iglesia como intrínsecamente misionera. Esta es la participación de los fieles en el oficio profético de Cristo. Tal labor corresponde a todos por igual en la Iglesia, pero la siempre repetida diferenciación interna en clérigos y laicos la ha distorsionado, creando un testimonio normativo y otro dependiente del primero. El clero, particularmente el Magisterio jerárquico, se reserva las decisiones sobre doctrina y moral, convirtiéndose en Iglesia docente, y el laicado debe acatarlas y actuarlas en el mundo en cuanto Iglesia que aprende. Sin duda que el ministerio eclesial cumple una tarea específica en este apartado, sirviendo a la unidad de la fe, la misma fe apostólica constantemente renovada y reinterpretada para hacerla inteligible al mundo cambiante al que está destinada. Pero servir a la unidad de la fe entre los cristianos, y a la conexión de ésta con la predicación original de los apóstoles, no significa monopolizar

54. Tradición Apostólica 15.

55. CIPRIANo, Epist. 14,4; 16,4; 19,2 . 
la correcta interpretación de la fe. A menos que no creamos que el Espíritu Santo habita en el corazón de cada creyente.

La presencia del Espíritu Santo en la Iglesia es una afirmación constante y gozosa del Nuevo Testamento. Los cristianos veían cumplirse en sí mismos las viejas promesas que hablaban de una efusión universal del Espíritu de Dios en la era mesiánica (J1 3,1-3; Jer 31,31ss; Hch 2,17; Heb 8,8). "Poseemos las primicias del Espíritu" (Rom 8,23) dirá Pablo. En la historia de la Iglesia que nos narran los Hechos el Espíritu es el protagonista principal, conduciéndola permanentemente en todos sus avatares (por ejemplo Hch 2,8; 15,8; 20,28). Y la teología del Espíritu Paráclito, que tras Jesús mantiene a los creyentes en la verdad (Jn 16,13s), es una de las notas características de los escritos juánicos (1Jn 2,20). Tras Agustín se generalizará la imagen del Espíritu como alma de la Iglesia ${ }^{56}$, su principio vital. La inhabitación del Espíritu Santo en los cristianos significa que su presencia asume una forma humana. Su acción se percibe a través del testimonio humano.

El Espíritu actúa desde el interior de cada cristiano. Ahí se encuadra la función profética de todos los miembros de la Iglesia. Una de las formas de explicitarla es a través del sensus fidei o sensus fidelium, el sentido de fe de los cristianos. Se trata de un venerable concepto de la teología cristiana57. Cuando a partir del sensus fidei se llega a la unanimidad entre cristianos en materia de fe, consensus fidelium, se determina uno de los modos de infalibilidad de la Iglesia (LG 12).

El sentido de la fe es algo más fácil de percibir que de explicar. San Hilario hablaba de "conciencia común de la fe" 58 y san Agustín de los "ojos de la fe" de los cristianos 59 . Newman de "una especie de instinto o phrónema radicado en el cuerpo místico de Cristo"60, y Congar de un "poder casi instintivo que tiene la fe para adherirse a su objeto, percibirlo, discernirlo"61.

Sería una facultad del individuo creyente que proviene de su fe, que le capacita para integrar ésta en su vida, esto es, para entenderla fundamentalmente y para saber actuar desde ella y en conformidad a ella. Solemos hablar de "sentido común" para expresar la capacidad natural y espontánea de toda persona, en virtud de su razón, para comprender los aspectos básicos de su vida cotidiana. No necesita una argumentación refleja o una previa

56. Agustin, Serm. 268,2.

57. Cf. Y. CongAR, Jalones para una teología del laicado, Barcelona 1961, 347-395.

58. HILARIO DE PoITIERs, De Synodis 65,77.

59. Agustin, Enarrationes in Psalmos 145,19; 90,II,13.

60. J.H. NEWMAN, On consulting the faithful in matters of doctrine: "The Rambler" (1859) 211.

61. Y. CONGAR, Jalones para una teología del laicado, 348. 
preparación intelectual, sino que viene dada en su ser racional. Podemos utilizar esto, aunque de modo analógico, para captar el significado del sensus fidei: aptitud del cristiano, coincidente con su fe, para conformar su vida a su credo. La analogía es necesaria porque la fe, al contrario que la razón, no viene dada de hecho en el cristiano, sino que es enseñada y asumida. Y ambas, la fe como la razón, son educadas o maduradas. Dicho esto, el sensus fidei, la capacidad del cristiano para encarar la vida, tomar decisiones desde la fe sobre los problemas que se le presentan, hay que pensarlo también como natural y espontáneo. Es decir, no necesita imprescindiblemente de indicaciones externas para resolver, en cuanto cristiano, los interrogantes a que se enfrenta. Como dice la Tradición Apostólica, clasificando a las personas cuyos oficios les impiden entrar en la Iglesia: "Si hemos omitido algo, las profesiones mismas os lo mostrarán, pues todos tenemos el Espíritu Santo"62.

Como siempre, la inferiorización en que se recluye a algunos cristianos, en realidad la mayoría de la Iglesia, por ser considerados laicos, ha hecho del sensus fidei una mera teoría. Parece suponérseles incapaces de hacer nada por sí mismos y la Jerarquía eclesiástica da la impresión de querer legislar y solucionar por sí sola todos los aspectos de su vida creyente. Esto es, también desde el punto de vista humano, contraproducente, pues los problemas propios requieren, al menos, una participación personal. Si se quiere fomentar una fe responsable habrá que admitir con todas sus consecuencias el sentido de fe de cada cristiano. En concreto, por ejemplo, en cuestiones matrimoniales y familiares (moral sexual, paternidad responsable), donde los más afectados son los que menos deciden. En asuntos doctrinales (posibilidad de disensión con la Jerarquía cuando no se ataca la unidad de la fe) y sociales (autonomía en la participación política, en la investigación científica). Cada cristiano sabrá afrontar tales cuestiones desde su fe, y dará así auténtico testimonio de ella.

Esto no significa que los cristianos posean la ciencia infusa, que no puedan equivocarse, que el sensus fidei no comporte riesgos para la Iglesia. Pero exactamente igual hay que decir del clericalismo. Al fin y al cabo, para

62. Tradición Apostólica 16; cf. también el núm. 43, conclusión del libro: "Si hemos omitido algo, queridos, Dios lo revelará a quienes sean dignos, pues Él conduce a la Iglesia para que llegue a puerto tranquilo". Es lo mismo que dice 1Jn 2,27: "La unción que de Él habéis recibido permanece en vosotros, y no necesitáis que nadie os enseñe". Naturalmente que estos textos entrañan cierta ambivalencia, y pueden derivarse peligros y abusos individualistas. Pero no se puede renunciar por ello a defender las consecuencias de la inhabitación del Espíritu en cada cristiano. 
terminar de modo original, la Iglesia no es sólo la Jerarquía, sino todos los cristianos. Su testimonio, sus aciertos y errores, corresponderán a todos. Creemos además, y por eso podemos asumir los riesgos, que está guiada por el Espíritu Santo.

Tomás MARcos

Estudio Teológico Agustiniano

Valladolid 